\title{
FAILURE ANALYSIS OF WELD-REPAIRED B-1900 TURBINE BLADE SHROUDS
}

\author{
Erik M. Mueller ${ }^{1}$, Luis Carney ${ }^{1}$, Sun Tai Ngin ${ }^{1}$, John L Yadon ${ }^{1}$ \\ ${ }^{1}$ NAVAIR, ISSC Code 4341, Building 793, NAS JAX, Jacksonville, FL 32212-0016
}

Keywords: Failure analysis, Welding, Hardface, Turbine blade

\begin{abstract}
Four turbine blades having a nominal B-1900 composition were submitted for failure analysis after cracks were detected or Znotch failure had occurred at the shroud. The blades were weld repaired at the shroud edges and returned to service, only to fail after several hours. The blade repairs involved machining away the original material, and then inert gas tungsten arc weld repairing with a Co-base hardface and B-1900 filler alloy. Analysis of the broken blades found that they had failed from fatigue. This fatigue was the result of cracks in the heat-affected zones of the blades created from liquation at the grain boundaries and residual stresses that could not be relieved through the lowductility weldments. Cracks also developed from precipitation of brittle secondary phases at the coating-weldment interdiffusion zone.
\end{abstract}

\section{Introduction}

Nickel-base superalloys are used throughout the aerospace industry because they meet the high-temperature mechanical requirements of the turbine section of modern aircraft engines. In order to maximize performance, the blades and vanes used in the turbine section have complex geometrical designs and casting procedures-precipitation-hardened nickel superalloy components cannot be forged. The rising costs of new turbine components due to processing and raw material expenses have created a desire to repair turbine blades and vanes already in service.

Wear and abrasion stemming from vibrations and hightemperature loads are experienced by the blades in the turbine section during operation. Of their many designed properties, high temperature wear resistance of $\mathrm{Ni}$ superalloys is usually overlooked. Hardfacing of the blade sections experiencing the most wear has been employed to prolong service life or repair damaged blades [1]. A hardface is commonly applied by inert gas welding the coating to the superalloy substrate or a plasma transferred arc overlay process [1-3]. Cobalt alloys, such as Stellite 694, are commonly used to impart wear resistance to the applied blade surfaces and can be hardened through solid-solution strengthening and carbide formation [1, 3-4].

Previous studies have documented the difficulty in welding precipitation-hardened Ni-based superalloys [5-7]. The weldability has been directly correlated to the $\mathrm{Ti}$ and $\mathrm{Al}$ concentrations [5] as well as the amount of boron, zirconium, and carbon present [7-8]. A Ti composition above $6 \mathrm{wt} \%$ and/or and Al composition above $3 \mathrm{wt} \%$ will make the alloy susceptible to intergranular cracking in the heat-affected zone (HAZ). The major cause of cracking is from constitutional liquation at the grain boundaries [9]. Liquation occurs when elements comprising second phases go into solution with the $\gamma$-Ni phase, forming lower melting eutectics at the grain boundaries. This most readily occurs when large amounts of $\gamma$, carbides, and/or borides are present at the grain boundaries [10-11]. In addition, excess precipitation of these secondary phases following weld repair can reduce the solid solution strength near the grain boundaries [12] and can create large shrinkage stresses during cooling [13], making them more susceptible to cracking. Other causes, such as high lattice mismatch between precipitate and matrix, and low ductility of the filler metal (in this study the hardface and filler), have been found to contribute to intergranular cracking [14].

Studies have been performed using stress-distribution models and X-ray diffraction [15] or neutron diffraction [16] that determined the maximum magnitude of residual stress is located in the heataffected zone less than $5 \mathrm{~mm}$ from the weld line. Post-weld heat treatments (PWHT) are often performed in order to relieve these stresses. However, these heat-treatments often initiate grain boundary microcracking due to the excess precipitation and liquation [8-11, 17]. This has also been linked to low ductility weld fillers that cannot yield to relieve residual stresses in the substrate HAZ [14, 18]. Careful control of the weld power and speed can reduce susceptibility to liquation, microporosity, and solidification cracking [19]. Careful control of grain orientation and grain geometry can also reduce crack propagation [20]. Overaging pre-weld heat treatments have also been found to be effective in reducing microcrack susceptibility in the HAZ [21].

In this study, turbine blades that had failed were repaired using a Stellite 694 hardface gas-tungsten arc weld (GTAW) repair. Some of the repaired blades had fractured after only a short time in service. The purpose of this study was to examine the repaired turbine blades to determine the root cause of failure of crack indications at the weld.

\section{Methods and Materials}

\section{Materials Received}

Four J52 $1^{\text {st }}$ stage turbine blades were submitted for inspection in this study. Three blades from one engine (labeled A, B, and C) while the fourth blade from another engine was labeled M720 (see Figures 1 and 2). Blades C and M720 had failed in service from a through crack on the convex side of the blade shroud near the Znotch. The locations of the crack indications found as described later are identified in Figures 1 and 2.

The base material for the blades is nominal B-1900 whose composition is Ni-8Cr-10Co-6Mo-6Al-4.3Ta-1.0Ti-0.015B$0.08 \mathrm{Zr}$ (weight \%). The blades were cast from a vacuuminduction melted (VIM) master heat, which was vacuum-arc remelted (VAR) before conventional casting. The castings were then heat-treated at $1080^{\circ} \mathrm{C}\left(1975^{\circ} \mathrm{F}\right)$ for $4 \mathrm{hr}$ in an inert atmosphere and then cooled.

Before the final heat treatment, the Z-notch tips were hardfaced by GTAW with Stellite 694 (Co-28Cr-5Ni-19.5W-1V) in the locations illustrated in Figure 3. After machining, the entire blade was then coated with a Cr-based vapor deposition to a minimum 
$20 \mathrm{wt} \% \mathrm{Cr}$ in the coated area, between $0.015 \mathrm{~mm}$ and $0.033 \mathrm{~mm}$ thick. Excluding the hardface, the rest of the shroud and part of the blade were coated with a pack-aluminization diffusion coating. Lastly, the casting undergoes the final heat treatment at $898^{\circ} \mathrm{C}\left(1650^{\circ} \mathrm{F}\right)$ for $10 \mathrm{hr}$ in an inert atmosphere, and is then air cooled.

In servicing the worn turbine parts, the blades were repaired by a welding new shroud tips and notches if cracks were detected between 0.5 and $0.9 \mathrm{~mm}$. This repair involved first machining away the coated areas and the cracked regions of the shroud edges. The tip adjacent to the Z-notch was then hardfaced with a Stellite 694 using manual shielded argon gas tungsten-arc welding. The conditions specified include preheating the blade to "the melting point of base metal," welding with a 15 to 28 A current, and a $1.25 \mathrm{~mm}$ gap between the surface and electrode tip. After, the remaining shroud area was to be built up with B-1900 filler using GTAW. The excess material was electrochemically ground to the dimensions required for the part. Finally, the material was recoated as described above before PWHT $\left(898^{\circ} \mathrm{C}\right.$ for $10 \mathrm{hr}$ in inert atmosphere).

\section{Experimental Procedure}

The blades submitted were first non-destructively inspected for cracks using fluorescent penetrant inspection (FPI) and radiography. The FPI was performed using IAW Type 1, Method D, Level 4 penetrant as detailed in ASTM E1417. The radiography was performed using a Tronics Pantak Conventional $\mathrm{X}$-Ray Unit. The radiographs were obtained digitally using a 120 $\mathrm{kV}, 4 \mathrm{~mA}, 1$ min exposure.

After non-destructive inspection, the blades were sectioned and analyzed. Several sections were mounted and polished to $0.3 \mu \mathrm{m}$ using a Struers Tegraforce-5 autopolisher. Mounted and unmounted specimens were analyzed using a variety of optical cameras, as well as a Zeiss Axiovert 200 MAT for optical metallography. Specimens were examined at higher magnification using a Camscan Maxim $2040 \mathrm{SL} \mathrm{LaB}_{6}$ SEM at 20 $\mathrm{kV}$. The SEM was equipped with an Oxford Link Pentafet energy-dispersive X-Ray spectrometer (EDS) and an Oxford Microspec WDX 600 wavelength-dispersive X-Ray spectrometer (WDS).

\section{Non-Destructive Inspection}

Non-destructive inspection using FPI revealed the following linear crack indications:

- $\quad$ Blade A: Underneath shroud at concave side

- $\quad$ Blade B: At center of Z-notch on both the convex and concave sides

- $\quad$ Blade C: Above the far right corner on the convex side

- Blade M720: On top of the shroud at weld joint near the fractured Z-notch (see Figure 3)

There was concern that sub-surface cracks could also be present. The blades were inspected using radiography. The radiographs (see Figure 4) revealed no cracks other than those previously determined by FPI. Due to the small size and complex geometry of the blade shrouds, other non-destructive techniques such as ultrasound and eddy-current were not successful.

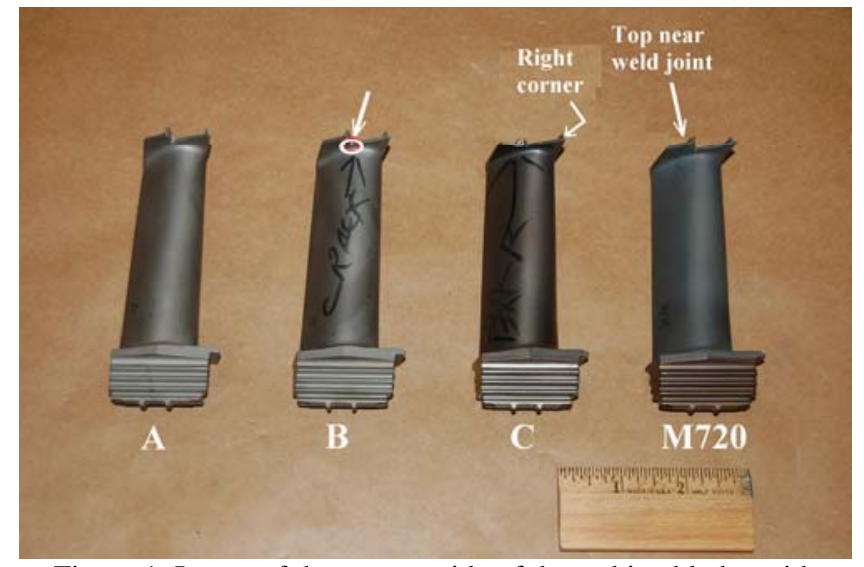

Figure 1. Image of the convex side of the turbine blades with showing the cracks observed through FPI.

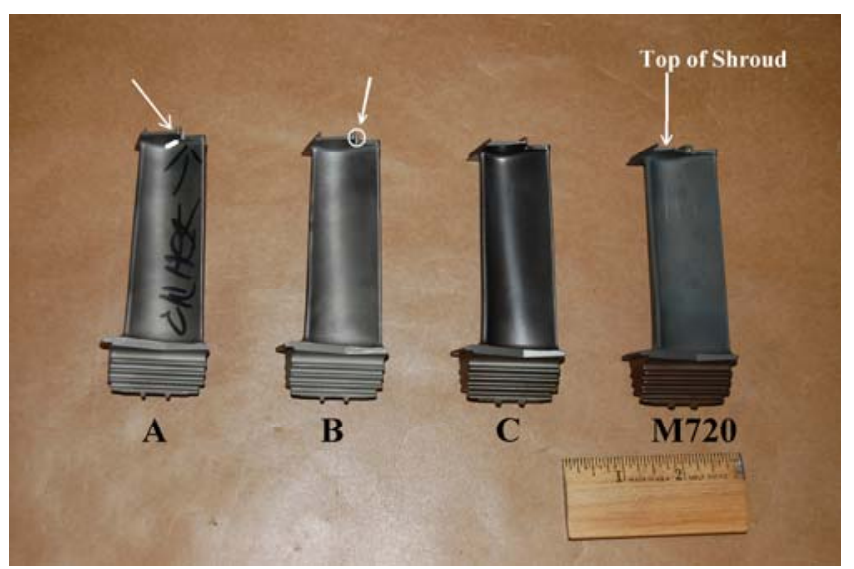

Figure 2. Image of the concave side of the turbine blades with showing the cracks observed through FPI.

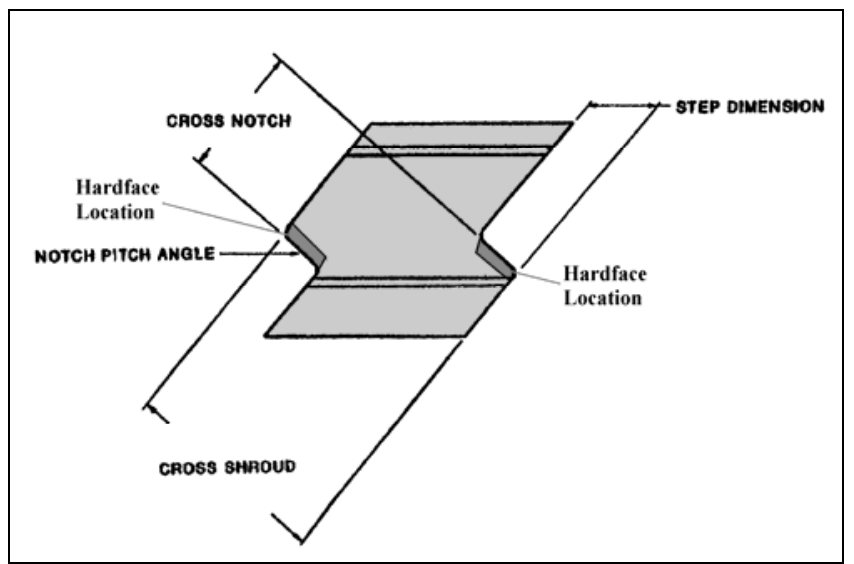

Figure 3. Illustration of the hardface locations of the turbine blade shrouds (dark grey). Other dimensional definitions are also identified for checking compliance with geometrical specifications. 


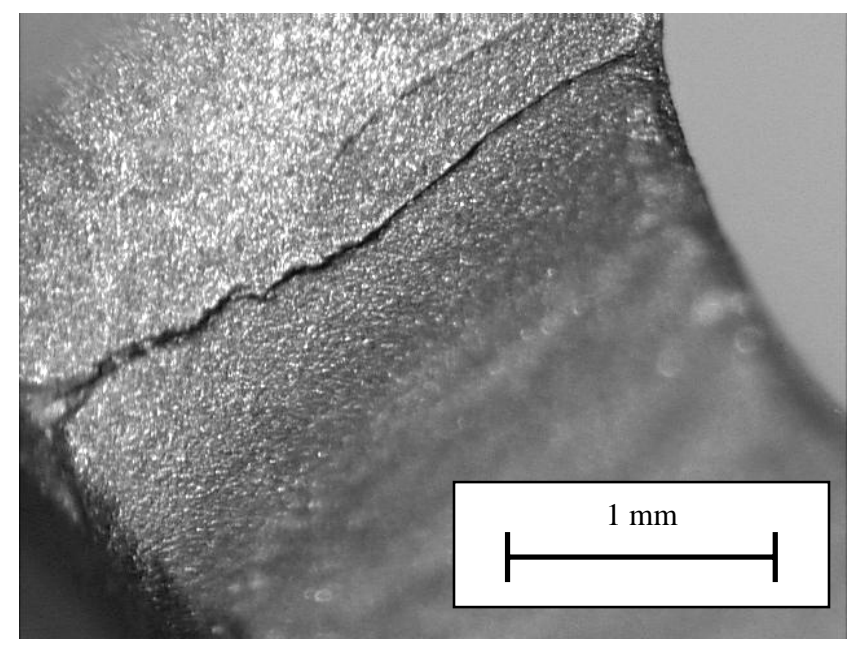

Figure 4. Photograph of the Z-Notch cracks on Blade B on the convex side. The crack was later found to have penetrated into the weld material.

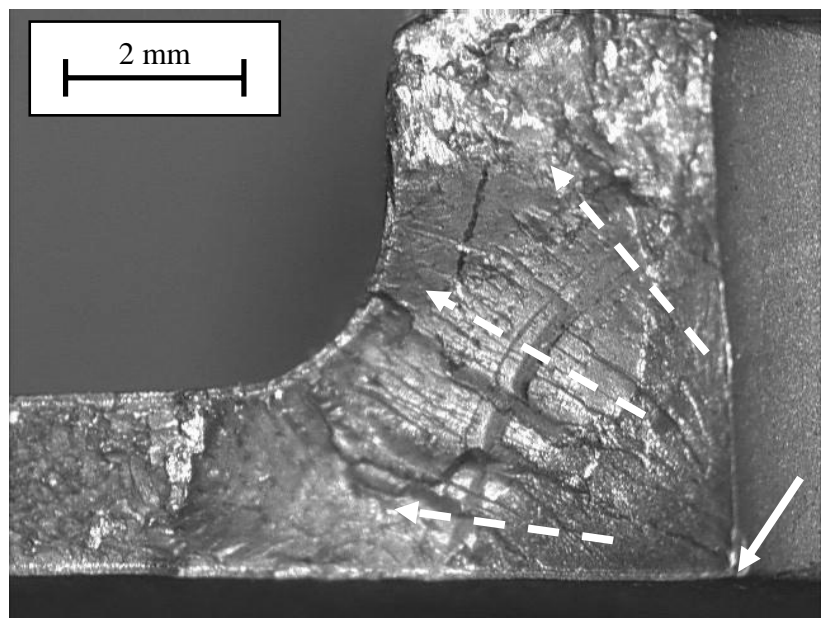

Figure 5. Photograph of the Z-notch fracture surface of the M720 blade. The origin is shown on the lower right corner (solid arrow), and propagates radially (dashed arrows).

\section{Failure Analysis Results}

\section{$\underline{\text { Visual Inspection }}$}

Figure 5 illustrates the fracture surface of blade M720 that had failed near the Z-notch. This surface, and the one from blade $\mathrm{C}$ (not pictured), ran parallel to the Z-notch tip tangent. The M720 fracture surface exhibited beach marks and fracture lines that ran back to the lower right corner of Figure 5. The fracture surface of the $\mathrm{C}$ blade was too damaged to make any conclusive observations at this level.

\section{$\underline{\text { Metallographic Inspection }}$}

Metallographic inspection of the blades revealed cracks that appeared to emanate on the surface and interior of the blade perpendicular to the top shroud surface. These flaws were found in the weld material as well as the substrate. Figure 6 shows an example one of the cracks identified from FPI. These surface

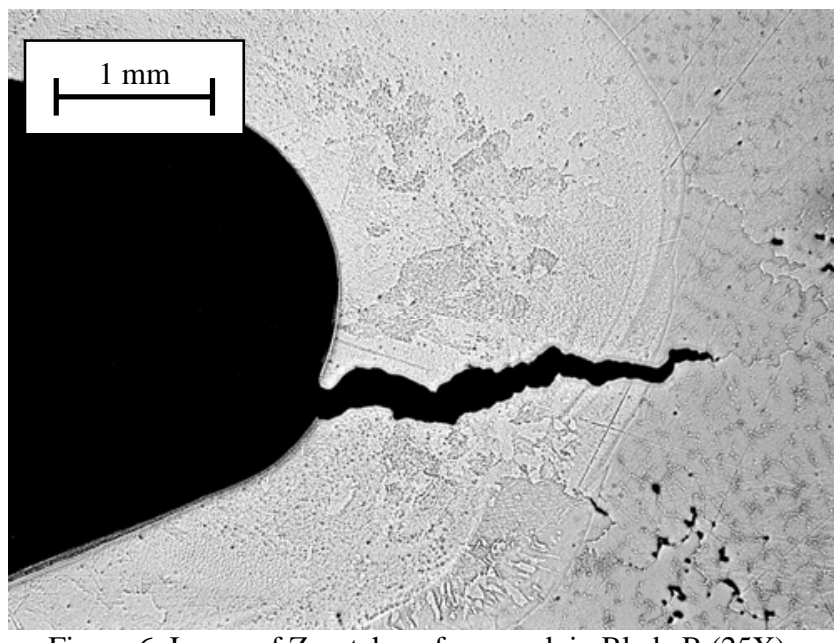

Figure 6. Image of Z-notch surface crack in Blade B (25X).

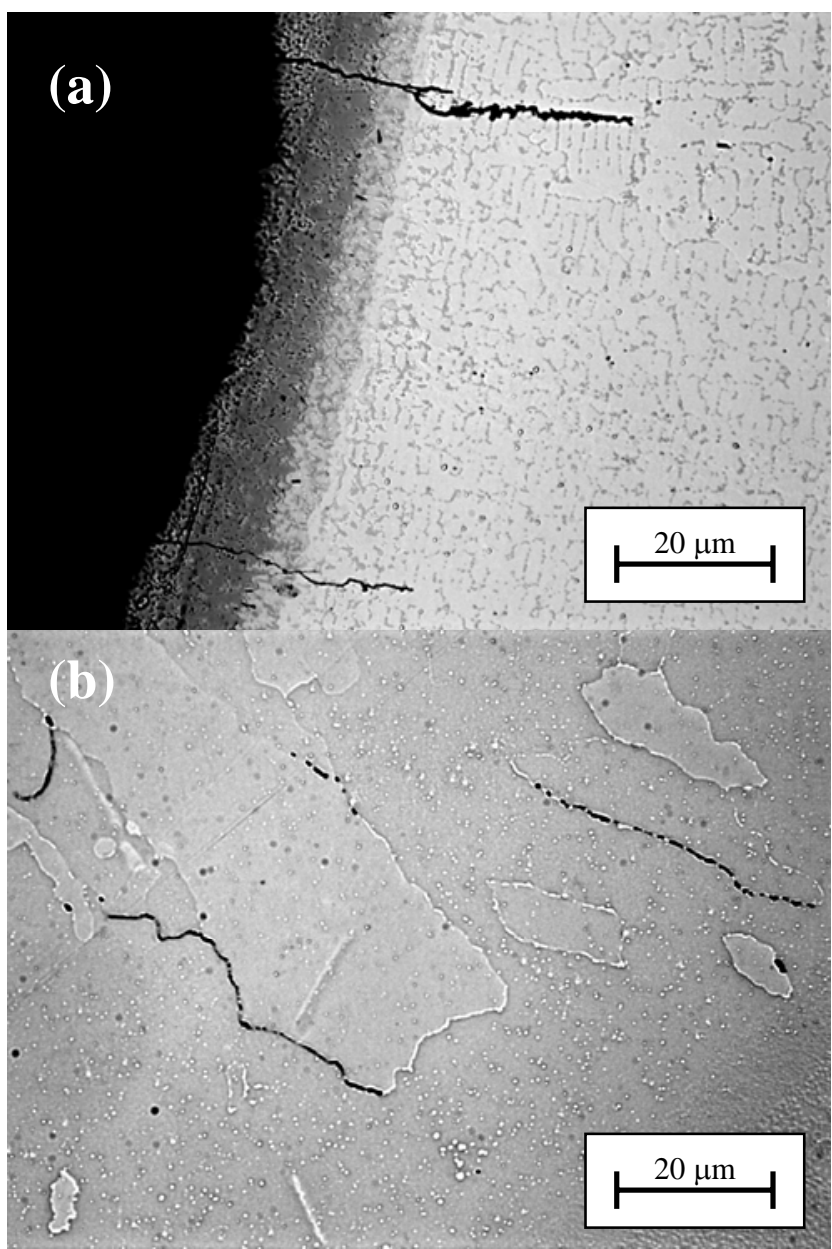

Figure 7. Images of cracks in blade B (a) along the interdendritic regions of the hardface and (b) along the grain boundaries in the filler material (1000X).

cracks were found to penetrate through the filler material as well as into the casting substrate. The cracks appeared to preferentially propagate along the grain boundaries in the base alloy, and along the interdendritic regions in the hardface welds (see Figure 7). 


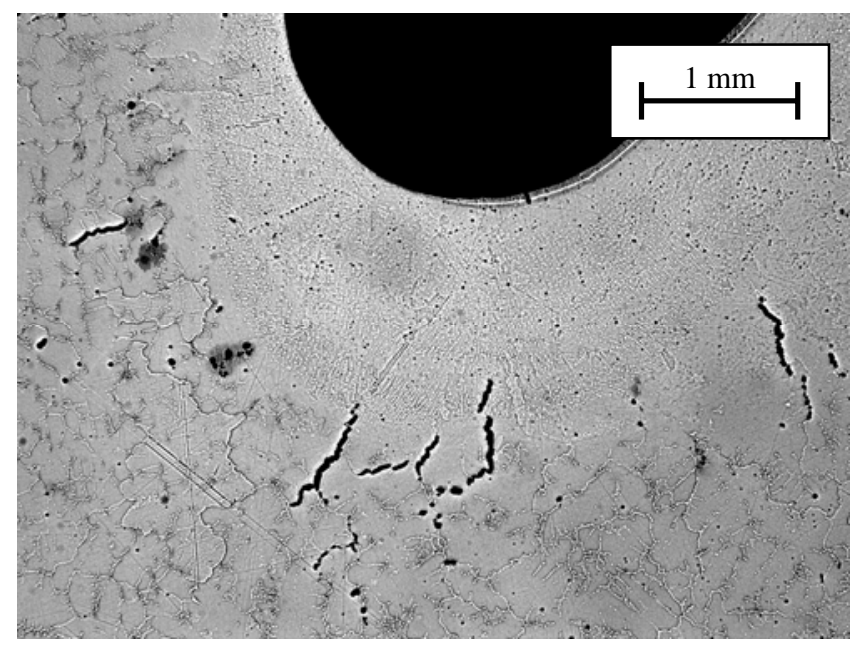

Figure 8. Optical image of hot cracks at the weld-alloy interface in the Z-notch of blade A (25X).

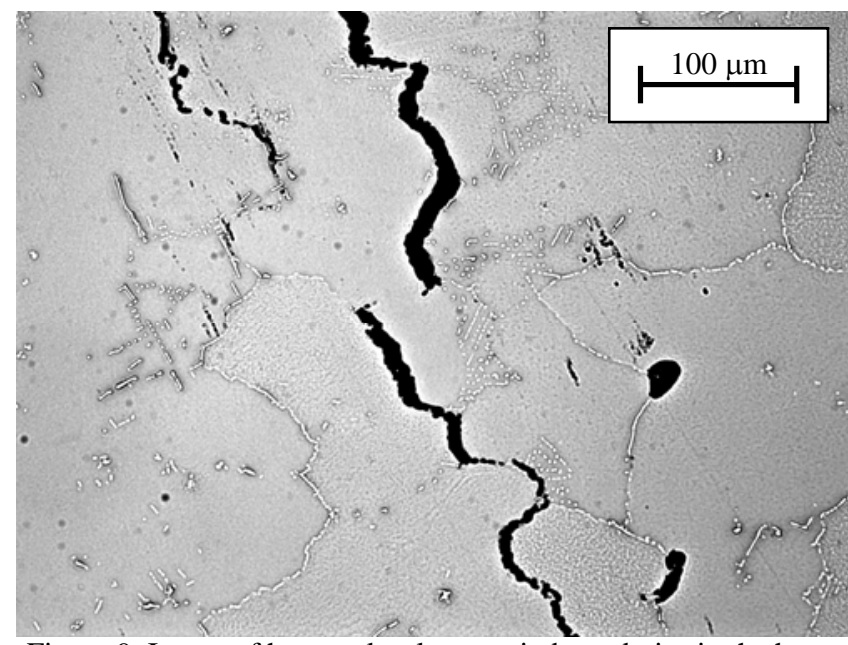

Figure 9. Image of hot cracks along grain boundaries in the heataffected zone. Carbides are present at the grain boundary (200X).

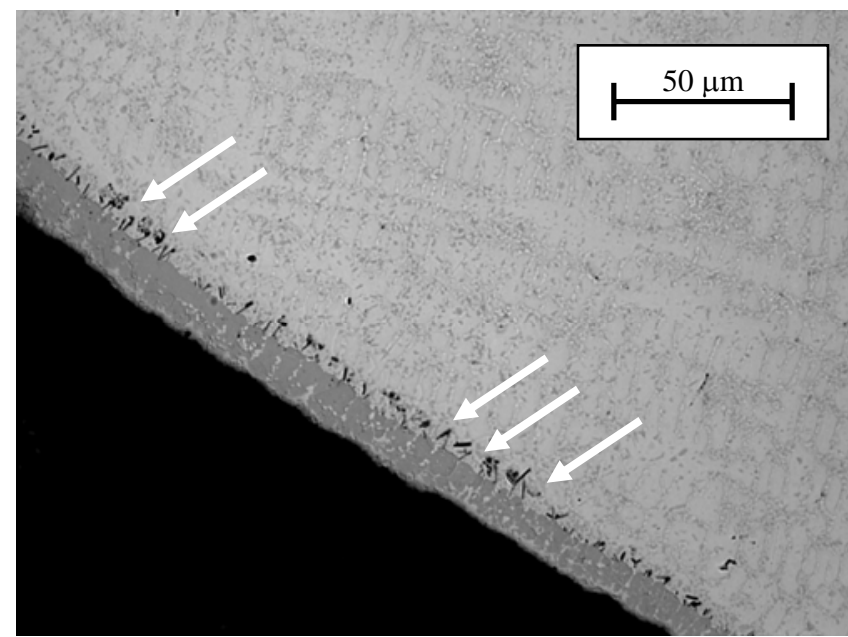

Figure 10. Image of the microcracks in the interdiffusion zone between the coating and the hardface in Blade B (500X). The microcracks are labeled (arrows).
At the weld-alloy interface, hot cracks were observed (see Figure 8). These cracks were always along the alloy grain boundaries (see Figure 9) or interdendritic regions of the hardface, which were generally normal to the surface direction. At the interdiffusion zone between the coatings and the weldments, small microcracks were observed (see Figure 10).

Indications of porosity were detected during the metallographic examination of these turbine blades. These are not likely to be artifacts, as the smooth dendrite surfaces can be seen in the pores. The morphology of the pores suggests shrinkage porosity developed during solidification. Since these pores were found not only near the weld but also in the bulk of the shroud, they were not considered to have formed due to the welding operation.

\section{$\underline{\text { SEM and X-Ray Microanalysis }}$}

Analysis of the fracture surface of blade M720 suggested failure from fatigue. Figure 11 shows fatigue striations identified on the fracture surface. The initiation site appears to be located, as shown in Figure 6, in the lower inner corner of the fracture surface (see Figure 12). No oxide inclusions or signs of corrosion pitting were found. At the ends of the fracture surface, away from the coating, dimple rupture was observed where the material overloaded. Near the surface, at the interdiffusion zone between the diffusion coating and weld material, signs of intergranular cracking and cleavage were observed (see Figure 13).

The fracture surface of blade $C$ could not be analyzed because of its poor condition. This was attributed to either extensive wear of the surface, rubbing before through fracture, or excessive deformation due to overheating.

Chemical analysis was performed using energy-dispersive X-ray spectroscopy (EDS). EDS confirmed the composition of the base alloy to be within the tolerances allowed for B-1900 in all the blades. In addition, the compositions of the hardface material and the welding filler material agreed with the composition tolerances of Stellite 694 and the B-1900, respectively.

The hot cracks, surface cracks, and porosity discovered through metallographic examination were analyzed using the SEM and EDS. The microstructure of the base metal, as well as the filler, showed blocky $\mathrm{TaC}$ and $\mathrm{TiC}$ carbides present at the grain boundaries and interdendritic regions. In addition, carbides made from $\mathrm{Cr}$, Mo, and $\mathrm{W}$ (either $\mathrm{MC}, \mathrm{M}_{23} \mathrm{C}_{6}$ or $\mathrm{M}_{6} \mathrm{C}$ ) were present as well (see Figure 14). Hot cracks propagated along these carbiderich boundaries in the substrate HAZ, and along the carbide-rich interdendritic regions in the hardface (see Figure 15).

Further inspection of the pores observed previously showed that they had a ruffled internal roughness and multiple blocky carbides on the surface (see Figure 16). EDS confirmed these to be MC ( $\mathrm{M}$ being Ta or Ti) carbides. Since MC carbides solidify from the melt, these pores were likely present in the original casting before welding.

Analysis of the surface at the diffusion coating revealed a multilayered structure as expected from two diffusion coatings. Figure 17 illustrates this microstructure. The phases were identified using a combination of EDS and WDS. The outermost layer is a $\beta$-NiAl layer with some excess $\alpha$-Cr throughout. The amount of 


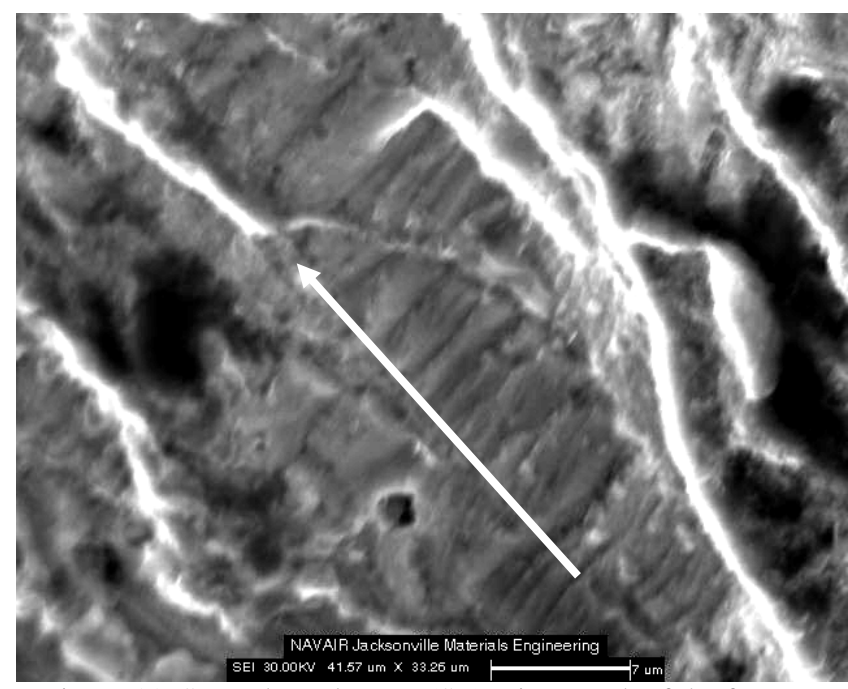

Figure 11. Secondary electron (SE) micrograph of the fracture surface of blade M720. The surface shows fatigue striations that propagate from lower right to upper left (arrow).

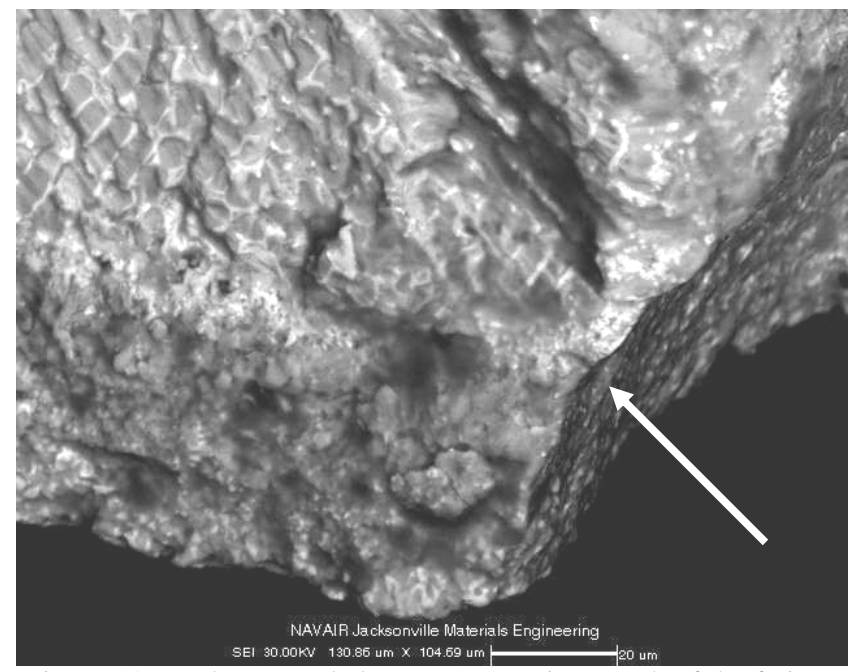

Figure 12. Backscattered electron (BE) micrograph of the fatigue crack initiation site on blade M720 (see arrow).

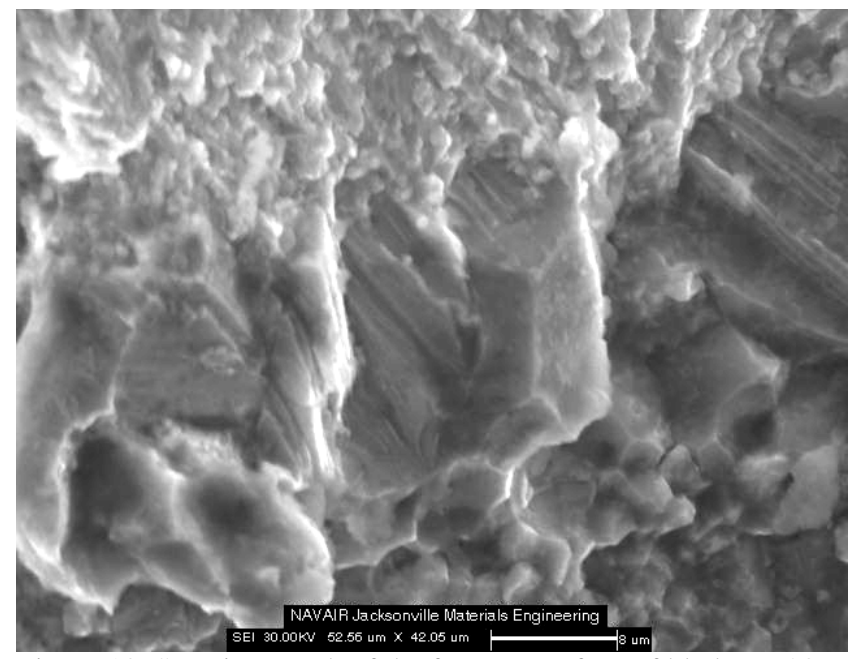

Figure 13. SE micrograph of the fracture surface of blade M720 at the interdiffusion zone between the weldment and coating.

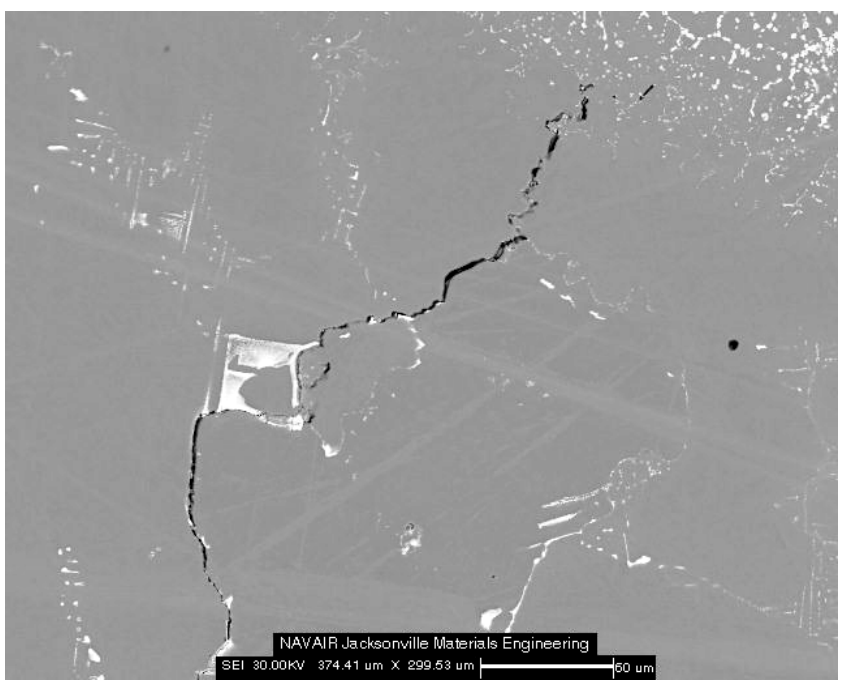

Figure 14. BE micrograph of a blade A hot crack in the HAZ

below the weld-alloy interface (upper right). The hot crack proceeds along a grain boundary containing a blocky MC carbide (light phase) and other carbides.

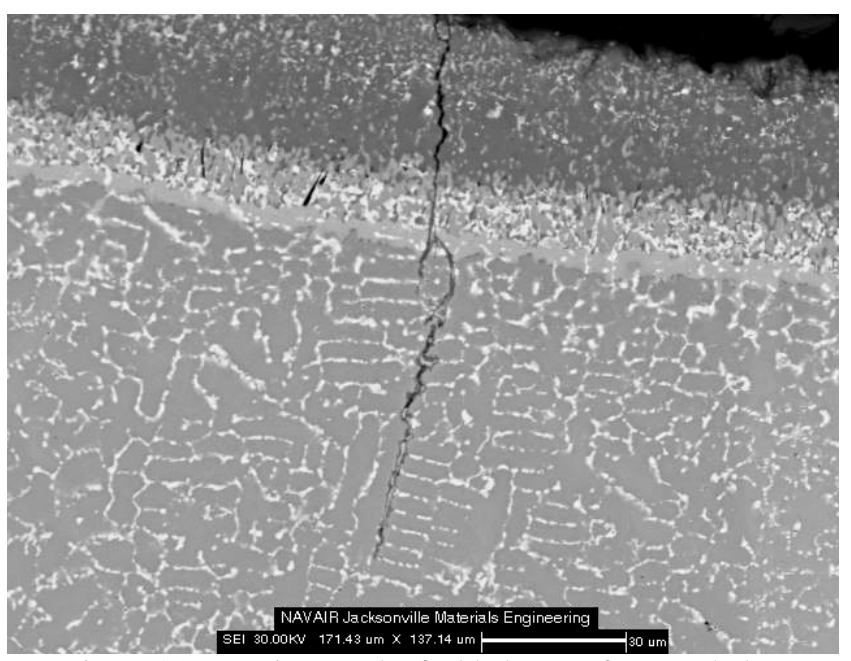

Figure 15. BE micrograph of a blade B surface crack that propagated into the hardface along the carbide-rich boundaries.

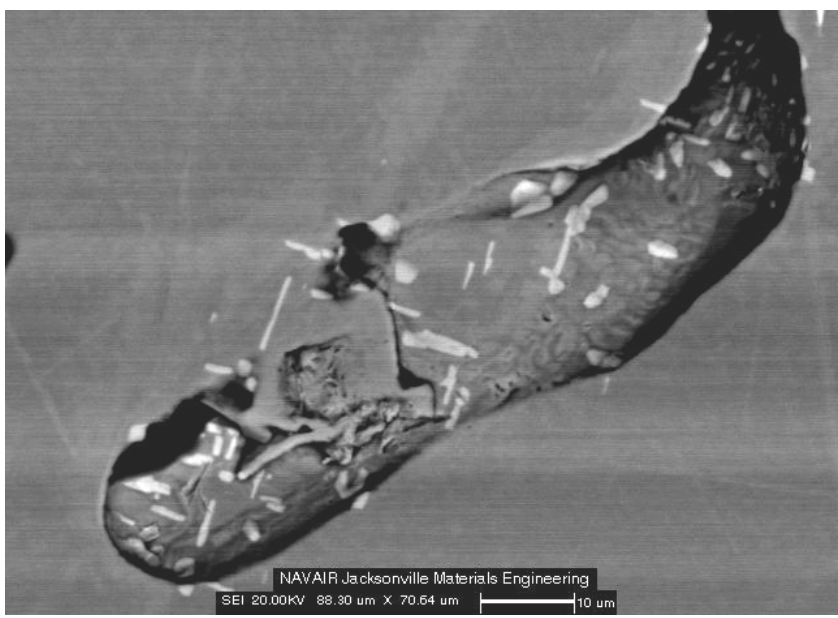

Figure 16. BE micrograph of a pore in blade A. Light phases are carbides present inside the pore. 
$\alpha$-Cr decreases with increasing distance from the surface. The middle layer is an interdiffusion zone between the $\mathrm{Cr}$ and $\mathrm{Al}$ diffusion coatings with a variety of phases, including $\gamma^{\prime}\left(\mathrm{Ni}_{3} \mathrm{Al}\right)$ as well as a large percentage of $\mathrm{Cr}$ and $\mathrm{Cr}-\mathrm{Mo}-\mathrm{Nb}$ phases. These phases may or may not be carbides. The compositions suggest that some chromium carbides, either $\mathrm{Cr}_{23} \mathrm{C}_{6}$ or $\mathrm{Cr}_{6} \mathrm{C}$, are present (with other metals substituting for $\mathrm{Cr}$ in varying amounts).

Additionally, a topologically-close packed (TCP) $\sigma$ phase, with an (Ni,Mo),Cr composition, was detected. No carbon or aluminum was detected in this phase. Multiple pores and cracks were found in this middle layer as well (Figure 18). The innermost layer is a $\mathrm{Cr}$-rich area of the $\gamma$-Ni matrix. The $\mathrm{Cr}$ content decreases away from the interdiffusion zone until it is the same as the base alloy.

Wavelength-dispersive X-ray spectroscopy (WDS) showed no signs of $\mathrm{S}, \mathrm{P}$, or other impurities commonly associated with hot cracking [7-8]. This includes scans of the diffusion coating, weldalloy interface, crack tips, and grain boundaries.

\section{$\underline{\text { Blade Geometry and Material Properties Verification }}$}

The dimensions of the shroud were compared against the drawing design specifications. The results are listed in Table I and refer to the dimensions shown in Figure 3. While generally conforming to specification, the cross notch is larger than called for, while the step dimension is less. The M720 blade appeared to deviate furthest from specification.

Microhardness tests were performed on the hardface weld area according to ASTM E384. The specimen hardface revealed an average hardness of $48 \mathrm{HRC}\left(510 \mathrm{HK}_{500 \mathrm{~g}}\right)$. This meets the minimum required hardness of $48 \mathrm{HRC}$.

Microhardness tests determined that the shroud material in the HAZ was softer than the remainder of the shroud. The hardness of the shroud adjacent to the weld filler was $30 \mathrm{HRC}\left(310 \mathrm{HK}_{500 \mathrm{~g}}\right)$ whereas the shroud hardness away from the weld, as well as the blade roots, was 35 HRC (349 HK $_{500 \mathrm{~g}}$ ). The B-1900 filler exhibited a hardness of $29 \mathrm{HRC}\left(304 \mathrm{HK}_{500 \mathrm{~g}}\right)$. There were no stated mechanical property requirements for these materials or blade areas.

\section{Analysis and Discussion}

The turbine blades shrouds that failed did so through fatigue propagation of cracks that initiated at or close to the surface inside the Z-notch. The physically intact, but cracked, blades exhibited linear defects on the surface inside the shroud Z-notch, as well as on the surface near the welds. Internal cracks were also observed often as hot cracks adjacent to the weld-alloy interface.

A number of issues led to the fatigue failure. It was difficult to determine which specific causes initiated crack formation, or merely aided propagation. The primary problem, as has been reported, appeared to be the low weldability of the B-1900 casting alloy. As shown in Figure 19, the Ti and Al content of the B-1900 compositions places it in the "difficult to weld" region [5, 22].

The low weldability of the substrate alloy is what led to the formation of hot cracks in the heat-affected zone. Cracks in the HAZ were primarily observed at the grain boundaries. Grain boundary cracking in Ni-base superalloys has been most

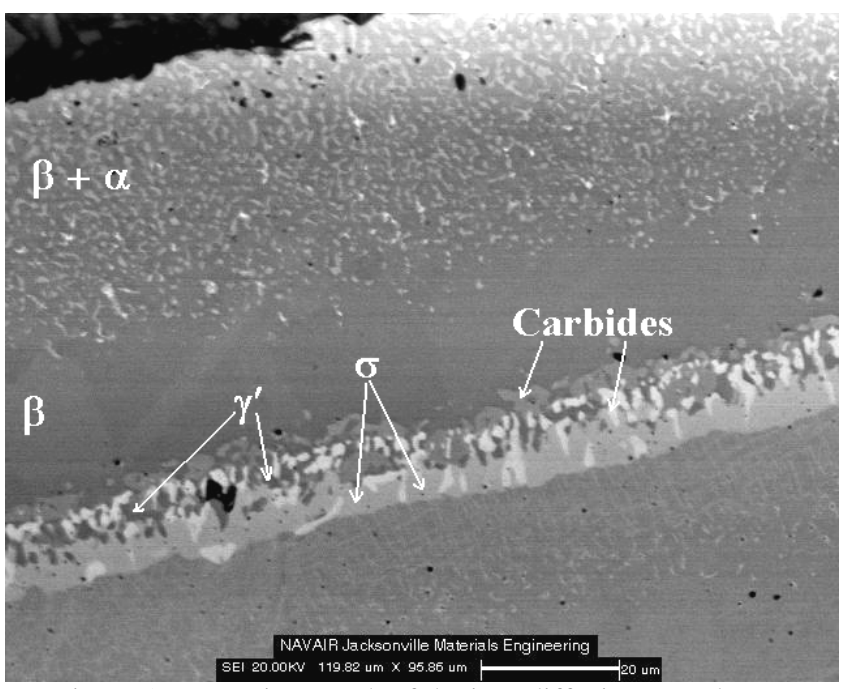

Figure 17. BE micrograph of the interdiffusion zone layers between the diffusion coatings and the hardface in blade A.

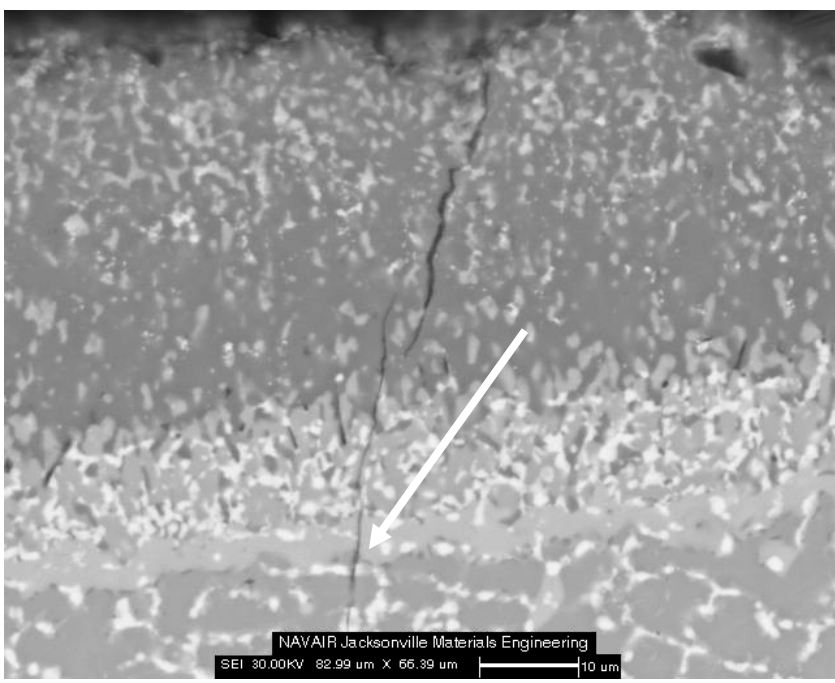

Figure 18. BE micrograph one of the interdiffusion zone cracks (arrow) is found in the $\sigma$ phase (light grey phase near arrow).

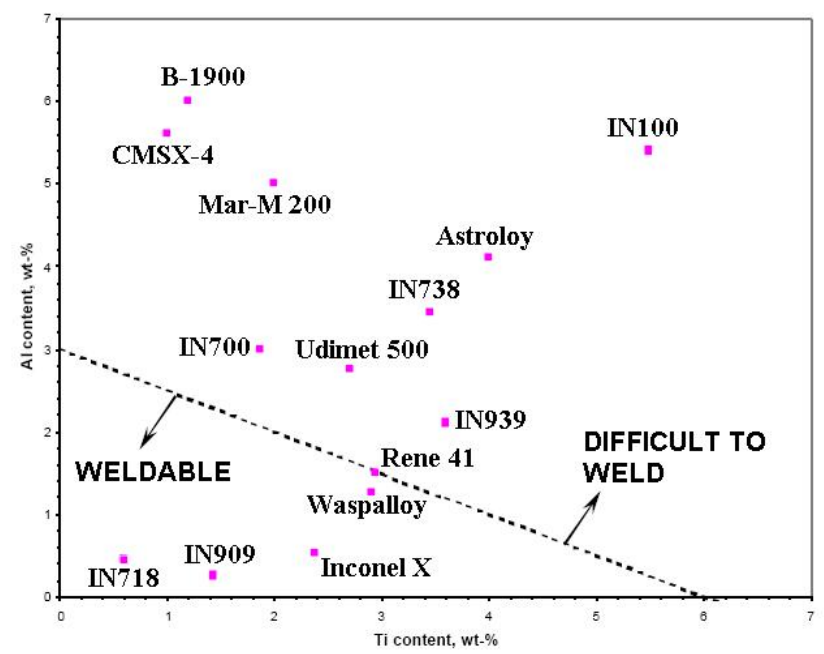

Figure 19. Weldability assessment diagram for various nickelbased superalloys [5, 22]. 
Table I. Critical dimensions measured on the turbine blade shrouds.

\begin{tabular}{|l|l|l|l|l|l|}
\hline & Drawing Requirements & Blade A & Blade B & Blade C & Blade M720 \\
\hline Cross Shroud (mm) & $26.90 \pm 0.05$ & 26.77 & 26.84 & 26.88 & 27.85 \\
\hline Cross Notch (mm) & $6.57 \pm 0.04$ & 6.985 & 7.018 & 6.820 & $5.883^{*}$ \\
\hline Step Dimension (mm) & $7.42 \pm 0.05^{\circ}$ & 6.678 & 6.985 & 6.683 & 6.668 \\
\hline Notch Pitch Angle & $30^{\circ} \pm 1^{\circ}$ & $28^{\circ}$ & $30^{\circ}$ & $30^{\circ}$ & $36^{\circ}$ \\
\hline
\end{tabular}

*Measurement of this notch is approximate due to most of the material missing from shroud.

commonly attributed to constitutional liquation [9-11]. The EDS system used in this study was unable to detect if there was an appreciable difference in B or $\mathrm{Zr}$ content near and away from the grain boundaries. However, the grain boundaries did contain a large amount of MC carbides, which can cause liquation [10-11].

Uncontrolled contraction during cooling of the weldment alloys was another major source of HAZ cracking. The filler alloy had the same composition as the of the cast shroud. Microhardness tests revealed that the weld filler and adjacent HAZ had similar hardness. The HAZ was softer than the rest of the casting, likely from improper PWHT and precipitation strengthening. Additionally, the hardface, which was designed to resist deformation, had a higher hardness than the HAZ or 'virgin' material. Welding precipitation-hardened $\mathrm{Ni}$ alloys that have lower ductility than the substrate are likely to crack $[14,18]$. In this case, cracking occurred at the weakest parts of the material: grain boundaries in the substrate HAZ and filler, and interdendritic regions in the hardface. These areas were replete with carbides that, while hard, are also brittle.

According to the drawing supplied, the hardface material was to be applied at the notch tip to impart increased wear resistance. However, the Co-based hardface was also observed inside the Znotch itself, and the hardface material may lack the toughness to protect against fatigue crack formation and propagation. The microstructure and composition of the hardface matched that expected from the design requirements and a previous study. There appeared to be little mixing of the hardface and substrate at the weld interface. This has been known to lead to TCP formation and cracking [3].

Of particular note is the impact the diffusion coatings had on crack initiation. SEM analysis revealed microscopic cracks, called leaders, at both the surface and the interdiffusion zone. Leaders are columnar voids between coating grains [23]. The outermost layer, as created from the pack aluminization, is mainly $\mathrm{NiAl}$. While this intermetallic has excellent oxidation resistance, it cannot plastically deform under an applied stress and will fracture [24]. At the Z-notch where the highest stress concentration is located, $\mathrm{NiAl}$ would be unable to relieve stresses in the HAZ or weldment.

In addition, TCP phase (in this case, $\sigma$ ) was detected at the interdiffusion zone between the coatings and substrate. Often present in stainless steels and superalloys, $\sigma$ usually forms in service from $\mathrm{M}_{23} \mathrm{C}_{6}$ carbides in alloys high in $\mathrm{Cr}$, Ta, $\mathrm{Nb}, \mathrm{W}$, and Mo. The base alloy, filler weld, and hardface were all enriched in these elements that appeared in highest concentrations at the interdiffusion zones. The formation of TCP could be enhanced by the $\mathrm{Cr}$ coating deposition. TCP phases such as $\sigma$ do not plastically deform and will fracture, especially at the grain or phase boundaries [25].
All these material defects, combined with the geometry of the shroud Z-notch, reduced the mechanical properties of the weldrepaired blades. This made the blades more susceptible to loads from any bending, twisting, or vibrating. Even if the material requirements are acceptable in other areas of the blade, the decreased performance the notch became the limiting factor.

All of these material and processing factors led to crack initiation and propagation that caused premature failure of these blades. For this engine, these blades are designed to operate at or around 1000 hours. All the blades inspected in this study failed two orders of magnitude lower than this.

There is a multitude of suggestions that could have extended the service life of these blades. First, tolerances should have been rigidly controlled in the weld repair with respect to preheating, cooling, and areas welded. The hardface welds should only have been performed on the notch tips and not on the inner radius of the notch itself. Proper substrate cleaning, pure filler materials, and low-impurity inert gases must be employed during the weld procedure. The composition of these blades put them in a range that is "difficult to weld" due to strain-age cracking. Therefore, all blades shrouds geometries needed to be inspected thoroughly before and after machining make sure they conformed to specification. None of the blades presented here conformed to all dimension tolerances investigated. A shroud that is too large or too small in one direction can cause undo stresses, vibration, and wear on it and the surrounding blades. An overaging pre-weld heat treatment, as has been previously employed [21], may have made the casting more weldable at the expense of some mechanical properties.

The application of the diffusion coatings was also considered to have been a contributing factor. The hardface was supposed to be masked during the coating process, but often had been coated. The phases formed from the coating appear to be opportune sites for crack initiation. In the future, the necessity of hightemperature corrosion resistance in these shroud sections should be carefully weighed against the lost fatigue life of the blade.

\section{Conclusions}

- $\quad$ Fracture of two of the submitted blades (M720, and likely blade $\mathrm{C}$ ) occurred by fatigue that initiated at the surface inside the Z-notch. The sharp corner in the respective areas as well as weld defects and improper diffusion coatings are considered to have been contributing factors.

- The heat-affected zones and weld areas exhibited hot cracking that was attributed to constitutional liquation and constrained shrinkage. No impurity elements were discovered in or near the welds. The grain boundaries contained carbides that are a commonly associated with liquation in the heat-affected zone. 
- The observed cracks were perpendicular to the surface and propagated internally along grain boundaries and interdendritic regions - the weakest areas of the substrate/filler and hardface, respectively.

- Cracks were observed at the surface and in the interdiffusion zone of the diffusion coatings, in the form of leaders and other microcracks. These were additional initiation sites for the fatigue failure.

- TCP phase was discovered in the interdiffusion zone between the diffusion coating and weld materials.

- Not all of the dimensional tolerances were met in the repair of these blades. This made the blades more susceptible to unexpected loads.

- Weld repairs of turbine blades with B-1900 or similar composition require very delicate and tightly controlled conditions. Failure to meet one or more requirements will create a predisposition for premature failure. Failure to meet one or more of these processing or quality control issues led to blade failure.

\section{Acknowledgements}

The authors would like to thank Warren Hansen and Ian Hawkins for performing the non-destructive inspections, as well as Stephen Binard for his assistance. The authors would also like to thank NAVAIR, United States Navy, and the Department of Defense for financial and facilities support.

\section{References}

1. E.F. Nippes, W.H. Cubberly, R.L. Stedfeld, K. Mills, J.R. Davis, and B.R. Sanders., eds., Metals Handbook Ninth Edition, Vol 6 (Metals Park, OH: American Society for Metals, 1983), 771-788

2. A.K. Jha, B.K. Prasad, R. Dasgupta, O.P. Modi, "Influence of Material Characteristics on the Abrasive Wear Response of Some Hardfacing Alloys,” Journal of Materials Engineering and Performance, 8 (1999), 190196

3. J. Day, X. Huang, M. Yao, "Study on CompositionInduced Microstructural Variation in the Interface Between Co-Based Hardfacing Alloys and IN738 NBased Superalloy," Journal of Materials Engineering and Performance, 13 (2004), 158-166

4. J.M. Drapier, A. Davin, A. Magnee, D. Coutsouradis, and L. Habraken, "Abrasion and Corrosion Resistant Cobalt Base Alloys for Hardfacing,” Wear, 33 (1975), 313-325

5. Metals Handbook (Desk Edition), (Metals Park, OH: American Society for Metals, 1985), 16-15-16-17.

6. D.S. Duvall, W.A. Owczarski, and C.P. Sullivan, “A Model for Heat-Affected Zone Cracking in Nickel Base Superalloys,” Welding Journal, 45 (1966) 145s-155s

7. D.S. Duvall and W.A. Owczarski, "Further HeatAffected-Zone Studies in Heat-Resistant Nickel Alloys,” Welding Journal, 46 (1967) 423-432

8. R. Thamburaj, W. Wallace, and J.A. Goldak, "Postweld heat-treatment cracking in superalloys," International Materials Reviews, 28 (1983), 1-22
9. J.J. Pepe and W.F. Savage, "Effects of Constitutional Liquation in 18Ni Maraging Steel Weldments,” Welding Journal, 46 (1967) 411s-422s

10. W.A. Owczarski, D.S. Duvall, and C.P. Sullivan, “A Model for Heat Affected Zone Cracking in Nickel-Base Superalloys,” Welding Journal, 45 (1966) 145s-155s

11. O.A. Ojo, N.L. Richards, and M.C. Chaturvedi, "Microstrucutral Study of Weld Fusion Zone of TIG Welded IN 783LC Nickel-Based Superalloy,” Scripta Materialia, 51 (2004), 683-688

12. M.J. Strum, L.T. Summers, and J.W. Morris Jr., "The Aging Response of a Welded Iron-Based Superalloy" Welding Journal, 62 (1983) 235s-242s

13. M.H. Haafkens and G.H. Matthey, "A new approach to the weldability of nickel-base as-cast and powder metallurgy superalloys,” Welding Journal, 61 (1982), 25-30.

14. K. Banerjee, N.L. Richards, and M.C. Chaturvedi, "Effect of Filler Alloys on Heat-Affected Zone Cracking in Preweld Heat-Treated IN-738 LC GasTungsten Arc Welds," Metallurgical and Materials Transactions A, 36A (2005), 1881-1890

15. M.V.R.S. Jensen, D. Dye, K.E. James, A.M. Korsunsky, S.M. Roberts, and R.C. Reed, "Residual Stresses in a Welded Superalloy Disc: Characterization using Synchrotron Diffraction and Numerical Process Modeling," Metallurgical and Materials Transactions A., 33A (2002), 2921-2931

16. R.C. Reed, S.M. Roberts, P.J. Withers, and D. Dye, "Determination of the residual strains and stresses in a tungsten inert gas welded sheet of IN718 superalloy using neutron diffraction” Journal of Strain Analysis, 35 (2000), 247-259

17. G.W. Meetham, "High temperature materials in gas turbine engines” Materials and Design, 9 (1988), 213219.

18. O.A. Ojo, N.L. Richards, M.C. Chaturvedi, "Study of the Fusion Zone and Heat-Affected Zone Microstructures in Tungsten Inert Gas-Welded INCONEL 738LC Superalloy,” Metallurgical and Materials Transactions A., 37A (2006), 421-433

19. D. Dye, O. Hunziker, and R.C. Reed, "Numerical Analysis of the Weldability of Superalloys," Acta Materialia, 49 (2001), 683-697

20. E.M. Lehockey, G. Palumbo, and P. Lin, "Improving the Weldability and Service Performance of Nickel and Iron-Based Superalloys by Grain Boundary Engineering," Metallurgical and Materials Transactions A, 29A (1998), 3069-3079

21. A. Thakur, N.L. Richards, and M.C. Chaturvedi, "On Crack-Free Welding of Cast Inconel 738” Inernational Journal of Joining Materials, 15 (2003), 21-25.

22. M.B. Henderson, D. Arrell, M. Heobel, R. Larsson, G. Marchant, "Nickel-Based Superalloy Welding Practices for Industrial Gas Turbine Applications," Science and Technology of Welding and Joining, 9 (2004), 13-21 
23. C.T. Sims, N.S. Stoloff, and W.C. Hagel, Superalloys II, (New York: John Wiley \& Sons, 1987), 364

24. K.H. Hahn and K. Vedula, "Room temperature tensile ductility in polycrystalline B2 NiAl," Scripta Materialia, 23 (1989), 7-12

25. C.T. Sims, N.S. Stoloff, and W.C. Hagel, Superalloys II, (New York: John Wiley \& Sons, 1987), 217-226 